UCRL-CR-114778

P.O. B098771

Phase Relationships and Stability of the $\mu$ - and $\zeta$-Phases in the Ag-Al-X (X=Zn, Ga, Ge) Systems

M.R. Paruchuri

T.B. Massalski

September 1993

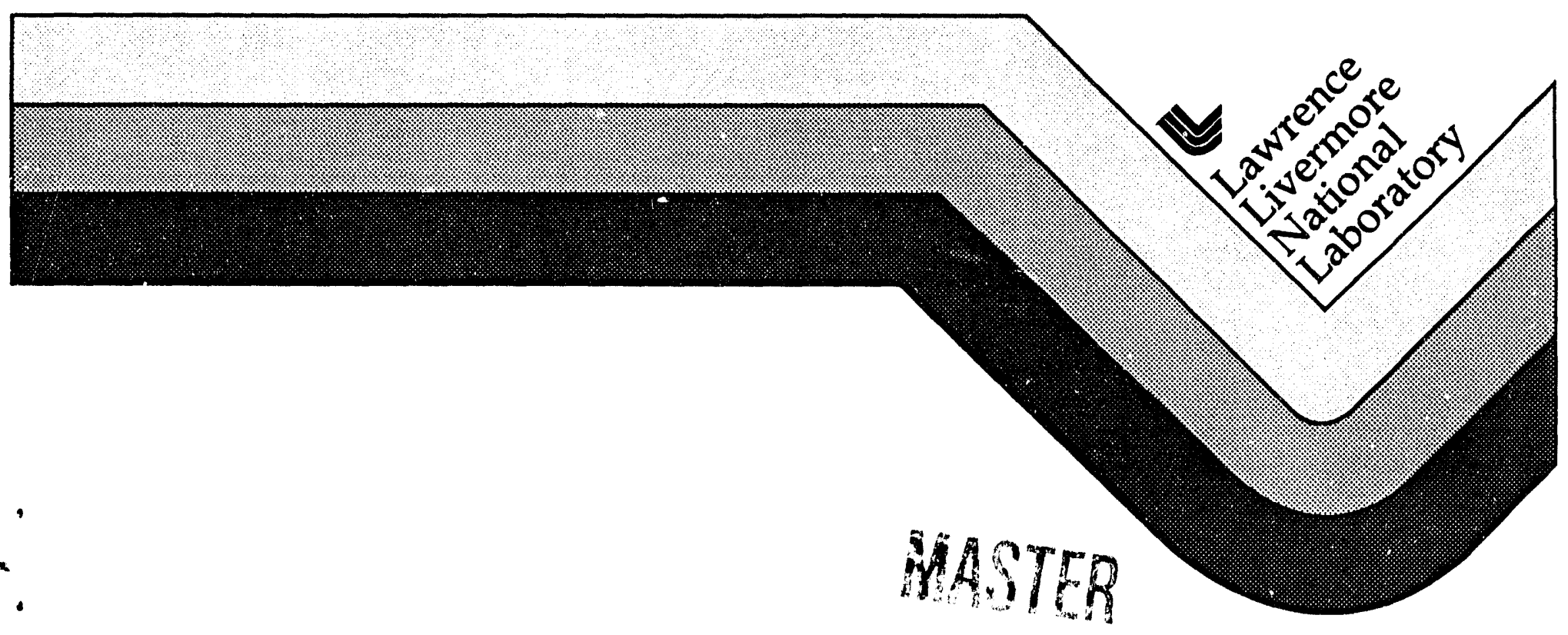

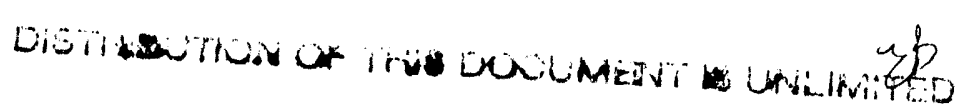




\section{DISCLAIMER}

Work performed under the auspices of the U.S. Department of Energy by Lawrence L.jvermore National Laboratory under contract number W-7405-ENG-48.

This document was prepared as an account of $n$ rk sponsored by an agency of the United States Government. Neither the United States Government nor the University of California nor any of their employees, makes any warranty, express or implied, or assumes any legal liability or responsibility for the accuracy, completeness, or usefulness of any information, apparatus, product, or process disclosed, or represents that its use would not infringe privately owned rights. Reference herein to any specific commercial products, process, or service by trade name, trademark, manufacturer, or otherwise, does not neressarily constitute or imply its endorsement, recommendation, or favoring by the United States Government or the University of California. The views and opinions of authors expressed herein do not neces. sarily state or reflect those of the United States Government or the University of California, and shall not be used for advertising or product endorsement purposes. 


\title{
Phase relationships and stability of the $\mu$ - and $\zeta$-phases in the Ag-Al-X (X=Zn, Ga, Ge) systems
}

\author{
M. R. Paruchuri and T. B. Massalski \\ Department of Materials Science and Engineering \\ Carnegie Mellon University \\ Pittsburgh, PA 15213, USA
}

\begin{abstract}
Details of phase relationships in three ternary systems, $\mathrm{Ag}-\mathrm{Al}-\mathrm{X}(\mathrm{X}=\mathrm{Zn}, \mathrm{Ga}, \mathrm{Ge})$ near the $\mathrm{Ag}$-rich corner at $400^{\circ} \mathrm{C}$ are presented. Metallography, $X$-ray diffraction, scanning electron microscopy and X-ray spectroscopy have been used to establish the respective isothermal sections at $400^{\circ} \mathrm{C}$. In each case, the $\mu$-phase and the $\zeta$ phase of the Ag-Al binary system extend into the ternary system and terminate at a three-phase region involving the $\mathrm{Ag}$-rich primary solid solution ( $\alpha_{1}$-phase) in the $\mathrm{Ag}$ $\mathrm{Al}-\mathrm{Zn}$ and $\mathrm{Ag}-\mathrm{Al}-\mathrm{Ga}$ systems, and the Ge-rich primary solid solution ( $\alpha_{2}$-phase) in the $\mathrm{Ag}-\mathrm{Al}-\mathrm{Ge}$ ternary system. The stability ranges of the $\mu$ and $\zeta$-phases follow approximately constant electron concentration lines. The solid solubilities of $\mathrm{Zn}, \mathrm{Ga}$ and $\mathrm{Ge}$ in the $\mu$-phase are relatively small, compared with those in the $\zeta$-phase (up to 18 at.\%). No ternary phase appears to exist in the Ag-rich portions studied in the three ternary systems.
\end{abstract}




\section{Introduction}

The binary system $\mathrm{Ag}-\mathrm{Al}$ involves three intermediate phases, $\mu$ (complex cubic, $\beta-\mathrm{Mn}), \zeta$ (hcp) and $\beta$ (bcc) $)^{1}$. The $\mu$-phase forms by a peritectoid reaction at $450^{\circ} \mathrm{C}$ and the $\beta$-phase is stable only at high temperatures, above $603^{\circ} \mathrm{C}$. The $\zeta$-phase forms peritectically at $726^{\circ} \mathrm{C}$. The ternary phase equilibria based on the $\mathrm{Ag}-\mathrm{Al}$ system at low temperatures, where only the $\mu$-phase and the $\zeta$-phase are stable, have been studied previously in a few systems; $\mathrm{Ag}-\mathrm{Al}-\mathrm{Mn}^{2}, \mathrm{Ag}-\mathrm{Al}-\mathrm{Cd}^{3}, \mathrm{Ag}-\mathrm{Al}-\mathrm{In}^{4}$ and $\mathrm{Ag}-\mathrm{Al}-\mathrm{Sn}^{5}$.

It is well known that the electron concentration is an important parameter in the Ag-rich systems with the polyvalent B-subgroup elements in the periodic table. It influences the ranges of stability and the types of the intermediate phases observed in these systems. The $\mu$-phase is present only in a few systems. The competition for stability between the $\mu$ and $\zeta$-phases in the binary system Ag-Al has been the subject of a detailed study some years ago ${ }^{6}$. Since the $\mu$-phase is stable only at low temperatures in the binary system, it is of interest to study its stability in relation to the $\zeta$-phase below the peritectoid temperature in the ternary systems containing some other B-subgroup elements of the periodic table. The elements $\mathrm{Zn}$ (lower valence than $\mathrm{Al}), \mathrm{Ge}$ (higher valence than $\mathrm{Al}$ ) and $\mathrm{Ga}$ (the same valence) provide suitable ternary additions. The $\mu$-phase also has special characteristics such as an extreme brittleness. In order to study possible changes of the mechanical behavior of the $\mu$-phase with ternary additions, the stability limits of the ternary extensions of this phase into the respective ternary systems must be considered first. In the present paper we report on the stability ranges of both the binary phases, $\mu$ and $\zeta$, when alloyed with $\mathrm{Zn}, \mathrm{Ga}$ and 
Ge. Ag-rich portions of the respective ternary equilibrium phase diagrams have been investigated at $400^{\circ} \mathrm{C}$, using metallographic and $X$-ray methods.

\section{Experimental Details}

Carefully weighed amounts of the starting pure metals were placed in narrow silica tubes, which were coated previously with a thin layer of carbon. The tubes were sealed after repeated evacuation and flushing with helium and then held in an oxyacetylene flame and shaken vigorously for $5 \mathrm{~min}$. after the contents had melted. The tubes were quenched in water. Nominal intended compositions of the alloys were accepted without chemical analysis if the weight losses during melting were less than 0.4 wt.\%. The nominal compositions of the alloys are given in Table 1. An initial homogenization treatment of $24 \mathrm{hrs}$. at $750^{\circ} \mathrm{C}$ was given to each alloy, followed by

iced water quenching. Homogenized samples were subsequently annealed at $400^{\circ} \mathrm{C}$ for six weeks followed by water quenching. Metallographic examination was done using optical microscopy and scanning electron microscopy. Compositional analysis of the phases present in the microstructure was done using energy dispersive X-ray spectroscopy (EDS). Filings obtained from bulk specimens were annealed at $400^{\circ} \mathrm{C}$ for $5 \mathrm{~min}$. for stress-relief and used for X-ray diffraction to identify the phases present. High angle reflections corresponding to $2 \theta$ values above $140^{\circ}$ were additionally recorded with a slow scanning speed and used to calculate the lattice parameters.

\section{Results and Discussion}

Partial isothermal sections for the systems $\mathrm{Ag}-\mathrm{Al}-\mathrm{Zn}$ and $\mathrm{Ag}-\mathrm{Al}-\mathrm{Ga}$ near the $\mathrm{Ag}$ rich corner and a complete isothermal section for the system Ag-Al-Ge at $400^{\circ} \mathrm{C}$ have been established. All the phases observed have been identified to be extensions of the phases found in the binary systems, as listed in Table 2. No ternary intermediate 
phases were found in the regions studied. Isothermal sections shown in Figs. 1 to 3 were constructed using tie line and tie triangle data after a phase-compositional analysis. Phase boundaries on the binary sides of each isothermal section were taken from the respective binary systems ${ }^{1}$.

As can be seen from Figs. 1,2 and 3 , the $\mu$ and $\zeta$-phases extend into the ternary systems and are in equilibrium with the Ag-rich primary solid solution ( $\alpha_{1}$-phase) in the $\mathrm{Ag}-\mathrm{Al}-\mathrm{Zn}$ and $\mathrm{Ag}-\mathrm{Al}-\mathrm{Ga}$ systems, and with Ge-rich primary solid solution ( $\alpha_{2}$ phase) in the Ag-Al-Ge system. Since the liquid phase is not involved in the Ag-Al-Ge system at $400^{\circ} \mathrm{C}$, a complete isothermal section was established in this case. The unexplored portions of the ternary systems $\mathrm{Ag}-\mathrm{Al}-\mathrm{Zn}$ and $\mathrm{Ag}-\mathrm{Al}-\mathrm{Ga}$ are sketched only tentatively in Figs. 1 and 2 and are based on the respective binary phase diagrams. The stability ranges of the $\mu$ and $\zeta$-phases generally follow constant electron concentration lines.

Fig. 4 shows back scattered and secondary electron images taken at different compositions in the three systems. The microstructures of three phase alloys $\left(\alpha_{1}+\mu+\right.$ $\zeta$ in the systems Ag-Al-Zn and Ag-Al-Ga are shown in Figs. 4(a) and 4(c), respectively. Light gray regions and dark gray regions correspond to $\alpha_{1}$ and $\zeta$-phases, respectively. The contrast regions at the grain boundaries are mostly the $\mu$-phase. The $\mu$-phase formed through a typical peritectoid reaction at the interface between the $\alpha_{1}$ and $\zeta$. The presence of the $\mu$-phase at the grain boundaries can be more clearly seen in the optical micrograph, which is also shown in Fig. 4(a). Secondary electron images could not produce sufficient contrast among different phases, as can be seen in Figs. 4(c) and $4(\mathrm{~d})$, because the compositions of $\alpha, \mu$ and $\zeta$ do not differ significantly from one 
another. So, the other microstructures in Figs. $4(b), 4(e)$ and $4(f)$ were observed using back scattered electrons.

The limits of solid solubility of the third element in $\mu$ and $\zeta$-phases of the Ag-AI system are given in Table 3. It can be seen that the $\zeta$-phase dissolves larger amounts of the third element than does the $\mu$-phase. A complete range of solid solubility between two binary $\mu$-phases in the Ag-Al-In system, as suggested by Campbell and Wagemann 4 , does not seem to be possible because a $\mu$-phase (with the $\beta-M n$ structure) is not stable in the Ag-In binary system. However, in systems where the hcp $\zeta$-phase is present in both binary systems, a continuous phase field has been reported in the ternary systems such as $\mathrm{Ag}-\mathrm{Al}-\mathrm{Cd}^{3}, \mathrm{Ag}-\mathrm{Al}-\mathrm{In}{ }^{4}$ and $\mathrm{Ag}-\mathrm{Al}-\mathrm{Sn}^{5}$.

The measured lattice parameters in the $\mu$-phase alloys of compositions close to the solid solubility limits are given in Table 4. Since, the silver content in these alloys is nearly the same as is in the binary $\mu$-phase, the change in the lattice parameter with one at.\% of the third element ( $\mathrm{Zn}, \mathrm{Ga}$ or $\mathrm{Ge}), \mathrm{da} / \mathrm{dc}$ can be calculated. The respective values for $\mathrm{Zn}, \mathrm{Ga}$ and $\mathrm{Ge}$ are $0.00002,0.00011$ and $0.00018 \mathrm{~nm} / \mathrm{at} . \%$. Ge addition is found to produce the largest lattice parameter increase, but the largest penetration into the ternary system occurs with $\mathrm{Ga}$ (up to 6.5 at.\%). Hence the rate at which the $\mu$ phase lattice becomes strained by ternary alloying additions does not seem to control the degree of phase penetration in the ternary system.

The general conclusion of the present work is that the $\mu$-phase of the Ag-Al binary system is quickly destabilized when ternary alloying additions are introduced. Hence, even though the electron concentration ratio e/a remains the main parameter determining the appearence of this $\beta-\mathrm{Mn}$ structure in an alloy system, secondary 
parameters appear to control its subsequent ranges of stability. We also note that the recently reported occurence of the $\beta-\mathrm{Mn}$ structure in the ternary Au-Sn-Cu system ${ }^{7,8}$ is surprising because the observed very narrow phase field of this structure not only follows closely a constant e/a line of 1.60 (20at.\% Sn), but the actual phase also occurs as a ternary phase in contrast to the present work. The e/a ratio within this phase in the Au-Sn-Cu system varies from 1.54 (18at.\% Sn) to 1.62 (20.5at.\% Sn) which is most surprising because all other $\mu$-phases reported in alloy systems based on the noble metals occur only within the narrow band of e/a between 1.40 and 1.54 . Clearly, further studies of this structure are of interest.

\section{Acknowledgements}

This work was supported in part by a grant from Lawrence Livermore National Laboratory, Livermore, CA, which is gratefully acknowledged. We are also grateful to Dr. W. H. Gourdin for many helpful discussions.

\section{Cited References}

1. T. B. Massalski, Binary Alloy Phase Diagrams, 2nd edition, ASM International, Materials Park, Ohio, USA (1990).

2. E. O. Hall, "The Silver-based Heusler Alloys", Phil. Mag., 4, 730-744 (1959).

3. T. B. Massalski, "A Note on the Stability of Intermediate Phases in the System SilverCadmium-Aluminium", J. Inst. Metals, 88, 232-234 (1959-60).

4. A. N. Campbell and R. Wagemann, "The Ternary System Silver-Indium-Aluminum", Can. J. Chem., 48, 3164-3172 (1970).

5. G. Petzow and G. Effenberg, "Ternary Alloys: a comprehensive compendium of evaluated constitutional data and phase diagrams", VCH Verlagsgesellschaft, Weinheim, FRG (1988). 
6. J. Bevk, J. Abriata and T. B. Massalski, "Low Temperature Specific Heats and the Relative Stability of the $\mu$ and $\zeta$ Phases in the Ag-Al System", Acta. Metall., 21, 16011613 (1973).

7. O. B. Karlsen, A. Kjekshus and E. Roest, "Ternary Phases in the System GoldCopper-Tin", Acta Chem. Scand., 44, 197-198 (1990).

8. O. B. Karlsen, A. Kjekshus and E. Roest, "The Ternary System Au-Cu-Sn", Acta Chem. Scand., 46, 147-156 (1992).

\section{Figures captions}

Fig. 1. Isothermal section of $\mathrm{Ag}-\mathrm{Al}-\mathrm{Zn}$ ternary system at $400^{\circ} \mathrm{C}$. Symbols show the alloys having different microstructures: $O$ single-phase, $O$ two-phase, ${ }^{\wedge}$ three-phase. Fig. 2. Isothermal section of Ag-Al-Ga ternary system at $400^{\circ} \mathrm{C}$. Symbols show the alloys having different microstructures: 0 single-phase, 0 two-phase, ${ }^{\wedge}$ three-phase. Fig. 3. Isothermal section of $\mathrm{Ag}-\mathrm{Al}-\mathrm{Ge}$ ternary system at $400^{\circ} \mathrm{C}$. Symbols show the alloys having different microstructures: $O$ single-phase, $O$ two-phase, ${ }^{\wedge}$ three-phase. Fig. 4. Microstructures of $\mathrm{Ag}-\mathrm{Al}-\mathrm{X}$ ( $\mathrm{Zn}, \mathrm{Ga}$ or $\mathrm{Ge}$ ) alloys, annealed at $400^{\circ} \mathrm{C}$ for 45 days. (a) Alloy composition: $77 \mathrm{Ag}, 19 \mathrm{Al}, 4$ at.\% $\mathrm{Zn}$; optical micrograph (OM) and back scattered electron image (BEI), observed phases $\left(\alpha_{1}+\mu+\zeta\right)$

(b) Alloy composition: $74 \mathrm{Ag}, 20 \mathrm{Al}, 6$ at.\%Zn; BEl, observed phases $\left(\alpha_{1}+\zeta\right)$

(c) Alloy composition: $77 \mathrm{Ag}, 15 \mathrm{Al}, 8$ at.\%Ga; secondary electron image (SEI), observed phases $\left(\alpha_{1}+\mu+\zeta\right)$

(d) Alloy composition: $77 \mathrm{Ag}, 11 \mathrm{Al}, 12$ at.\% Ga; SEl, observed phases $\left(\alpha_{1}+\zeta\right)$

(e) Alloy composition: $74 \mathrm{Ag}, 20 \mathrm{Al}, 6$ at. $\% \mathrm{Ge}$; BEl, observed phases $\left(\mu+\zeta+\alpha_{2}\right)$

(f) Alloy composition: $20 \mathrm{Ag}, 40 \mathrm{Al}, 40$ at. $\% \mathrm{Ge}$; BEl, observed phases $\left(\zeta+\alpha_{2}+\alpha_{3}\right)$ 
Table 1: Nominal compositions of the alloys studied and the phases present

\begin{tabular}{|c|c|c|c|c|c|c|}
\hline \multirow{2}{*}{$\begin{array}{l}\text { Alloy } \\
\text { no. }\end{array}$} & \multicolumn{5}{|c|}{ Nominal composition (at.\%) } & \multirow[t]{2}{*}{ Phases present } \\
\hline & $\mathrm{Ag}$ & Al & $\mathrm{Zn}$ & $\mathrm{Ga}$ & $\mathrm{Ge}$ & \\
\hline A1 & 77 & 23 & - & - & - & $\mu$ \\
\hline $\mathrm{Z1}$ & 80 & 18 & 02 & - & - & $\alpha_{1}+\mu$ \\
\hline $\mathrm{Z2}$ & 80 & 16 & 04 & - & - & $\alpha_{1}$ \\
\hline$Z 3$ & 80 & 14 & 06 & - & - & $\alpha_{1}$ \\
\hline $\mathbf{Z 4}$ & 80 & 12 & 08 & - & - & $\alpha_{1}$ \\
\hline $\mathbf{Z 5}$ & 77 & 22.5 & 0.5 & - & - & $\mu$ \\
\hline Z6 & 77 & 21 & 02 & - & - & $\alpha_{1}+\mu+\zeta$ \\
\hline $\mathbf{Z 7}$ & 77 & 19 & 04 & - & - & $\alpha_{1}+\mu+\zeta$ \\
\hline $\mathbf{Z 8}$ & 77 & 17 & 06 & - & - & $\alpha_{1}+\zeta$ \\
\hline Z9 & 77 & 15 & 08 & - & - & $\alpha_{1}$ \\
\hline $\mathbf{Z 1 0}$ & 74 & 24 & 02 & - & - & $\mu+\zeta$ \\
\hline $\mathbf{Z 1 1}$ & 74 & 22 & 04 & - & - & $\alpha_{1}+\mu+\zeta$ \\
\hline $\mathrm{Z12}$ & 74 & 20 & 06 & - & - & $\alpha_{1}+\zeta$ \\
\hline $\mathrm{Z13}$ & 74 & 18 & 08 & - & - & $\alpha_{1}+\zeta$ \\
\hline Ga1 & 80 & 16 & - & 04 & - & $\alpha_{1}+\mu$ \\
\hline Ga2 & 80 & 12 & - & 08 & - & $\alpha_{1}+\mu+\zeta$ \\
\hline Ga3 & 80 & 08 & - & 12 & - & $\alpha_{1}+\zeta$ \\
\hline Ga4 & 80 & 04 & - & 16 & - & $\alpha_{1}+\zeta_{1}$ \\
\hline Ga5 & 77 & 19 & - & 04 & - & $\mu$ \\
\hline Ga6 & 77 & 15 & - & 08 & - & $\alpha_{1}+\mu+\zeta$ \\
\hline Ga7 & 77 & 11 & - & 12 & - & $\alpha_{1}+\zeta$ \\
\hline
\end{tabular}




$\begin{array}{lllllll}\text { Ga8 } & 77 & 07 & - & 16 & - & \alpha_{1}+\zeta_{1} \\ \text { Ga9 } & 74 & 21 & - & 05 & - & \mu+\zeta \\ \text { Ga10 } & 74 & 16 & - & 10 & - & \alpha_{1}+\zeta \\ \text { Ga11 } & 74 & 11 & - & 15 & - & \alpha_{1}+\zeta \\ \text { Ga12 } & 65 & 20 & - & 15 & - & \zeta \\ \text { Ge1 } & 80 & 18 & - & - & 02 & \alpha_{1}+\mu+\alpha_{2} \\ \text { Ge2 } & 80 & 14 & - & - & 06 & \alpha_{1}+\alpha_{2} \\ \text { Ge3 } & 80 & 12 & - & - & 08 & \alpha_{1}+\alpha_{2} \\ \text { Ge4 } & 77 & 21 & - & - & 02 & \mu \\ \text { Ge5 } & 77 & 17 & - & - & 06 & \alpha_{1}+\mu+\alpha_{2} \\ & & & & & & \\ \text { Ge6 } & 74 & 24 & - & - & 02 & \mu+\zeta \\ \text { Ge7 } & 74 & 20 & - & - & 06 & \mu+\zeta+\alpha_{2} \\ \text { Ge8 } & 74 & 18 & - & - & 08 & \mu+\alpha_{2} \\ \text { Ge9 } & 60 & 10 & - & - & 30 & \alpha_{1}+\alpha_{2} \\ \text { Ge10 } & 17 & 62 & - & - & 21 & \zeta+\alpha_{2}+\alpha_{3} \\ \text { Ge11 } & 20 & 40 & - & - & 40 & \zeta+\alpha_{2}+\alpha_{3} \\ \ldots \ldots \ldots \ldots \ldots \ldots\end{array}$

Table 2: Crystal structure identification of the phases

\begin{tabular}{ll} 
Phase & \multicolumn{1}{c}{ Structure } \\
\hline$\alpha_{1}$ & Ag-rich primary solid solution: FCC \\
$\mu$ & Complex cubic: $\beta-M n$ \\
$\zeta$ & HCP \\
$\zeta_{1}$ & Hexagonal \\
$\alpha_{2}$ & Ge-rich primary solid solution: Diamond \\
$\alpha_{3}$ & Al-rich primary solid solution: FCC
\end{tabular}


Table 3: Solid solubilities of third elements in $\mu$ and $\zeta$ phases of the Ag-Al system

\begin{tabular}{|c|c|c|c|c|}
\hline \multirow[t]{2}{*}{ Alloying element } & \multicolumn{2}{|c|}{ Solubility limit (at.\%) } & \multicolumn{2}{|c|}{ Temperature Reference } \\
\hline & in $\mu$ phase & in $\zeta$ phase & $\left({ }^{\circ} \mathrm{C}\right)$ & \\
\hline $\mathrm{Zn}$ & 0.8 & 9.0 & 400 & present study \\
\hline Ga & 6.5 & 18.0 & 400 & present study \\
\hline Ge & 2.5 & 10.0 & 400 & present study \\
\hline Cd & 0.5 & C.S.S. & 438 & (3) \\
\hline $\ln$ & - & c.s.s. & 143 & (4) \\
\hline Sn & 1.0 & c.s.s. & 25 & (5) \\
\hline Mn & 5.0 & 4.0 & 400 & (2) \\
\hline
\end{tabular}

c.s.s.: complete solid solubility

Table 4: Lattice parameters of a few $\mu$ phase ternary alloys.

\begin{tabular}{|c|c|c|c|c|c|}
\hline \multicolumn{3}{|c|}{ Nominal composition (at.\%) } & \multirow[t]{2}{*}{$e / a$} & \multirow{2}{*}{$\begin{array}{l}\text { Lattice parameter } \\
\text { (nm) }\end{array}$} & \multirow[t]{2}{*}{$d a / d c$} \\
\hline $\mathrm{Ag}$ & Al & third element & & & \\
\hline 77 & 23.0 & - & 1.460 & 0.69390 & - \\
\hline 77 & 22.5 & $0.5 \mathrm{Zn}$ & 1.455 & 0.69391 & 0.00002 \\
\hline 77 & 19.0 & $4.0 \mathrm{Ga}$ & 1.460 & 0.69435 & 0.00011 \\
\hline 77 & 21.0 & $2.0 \mathrm{Ge}$ & 1.480 & 0.69425 & 0.00018 \\
\hline
\end{tabular}


Ag. Zn Phase Diagram

Ag. Al Phase Diagram
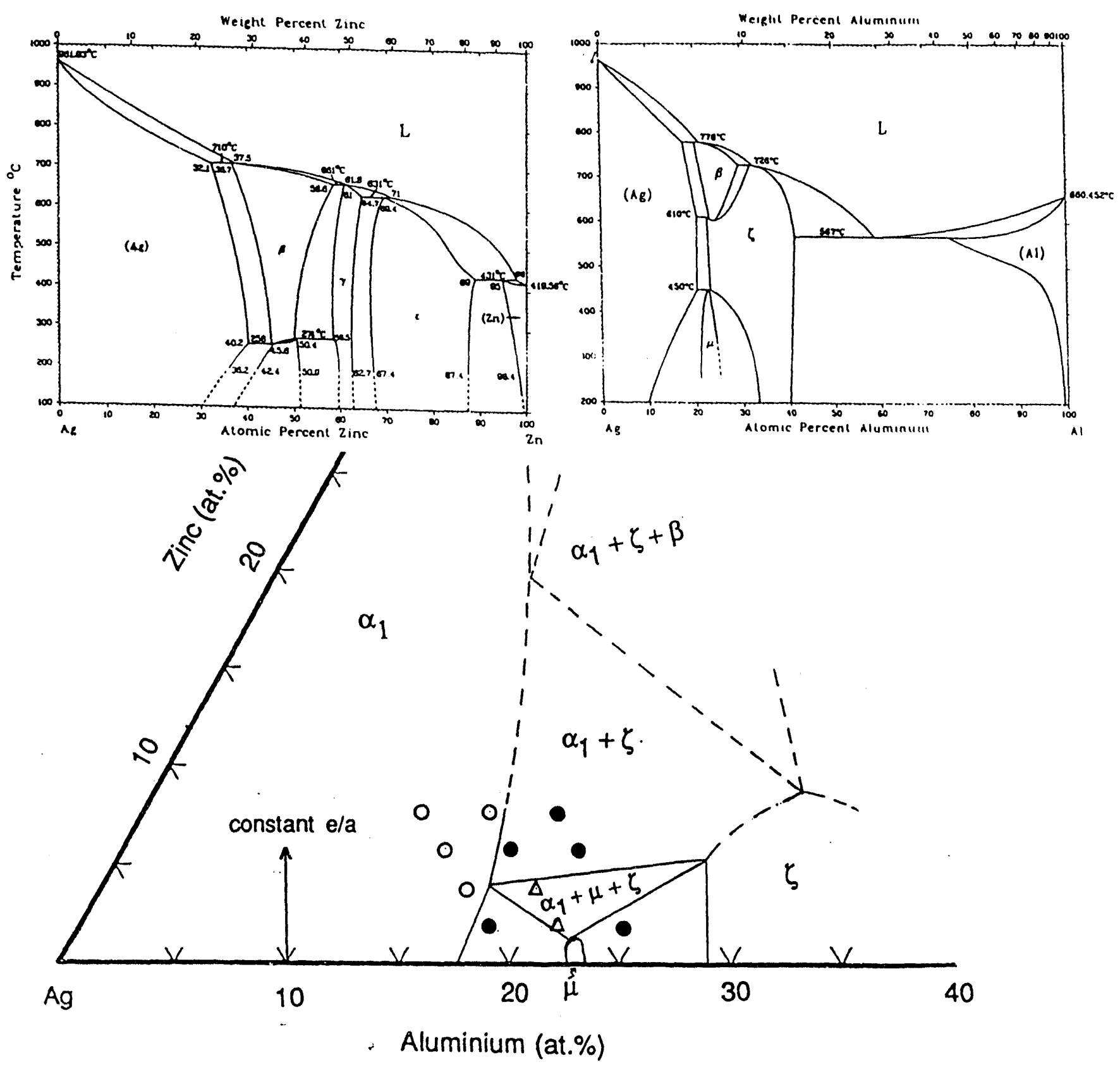

Fig. 1 


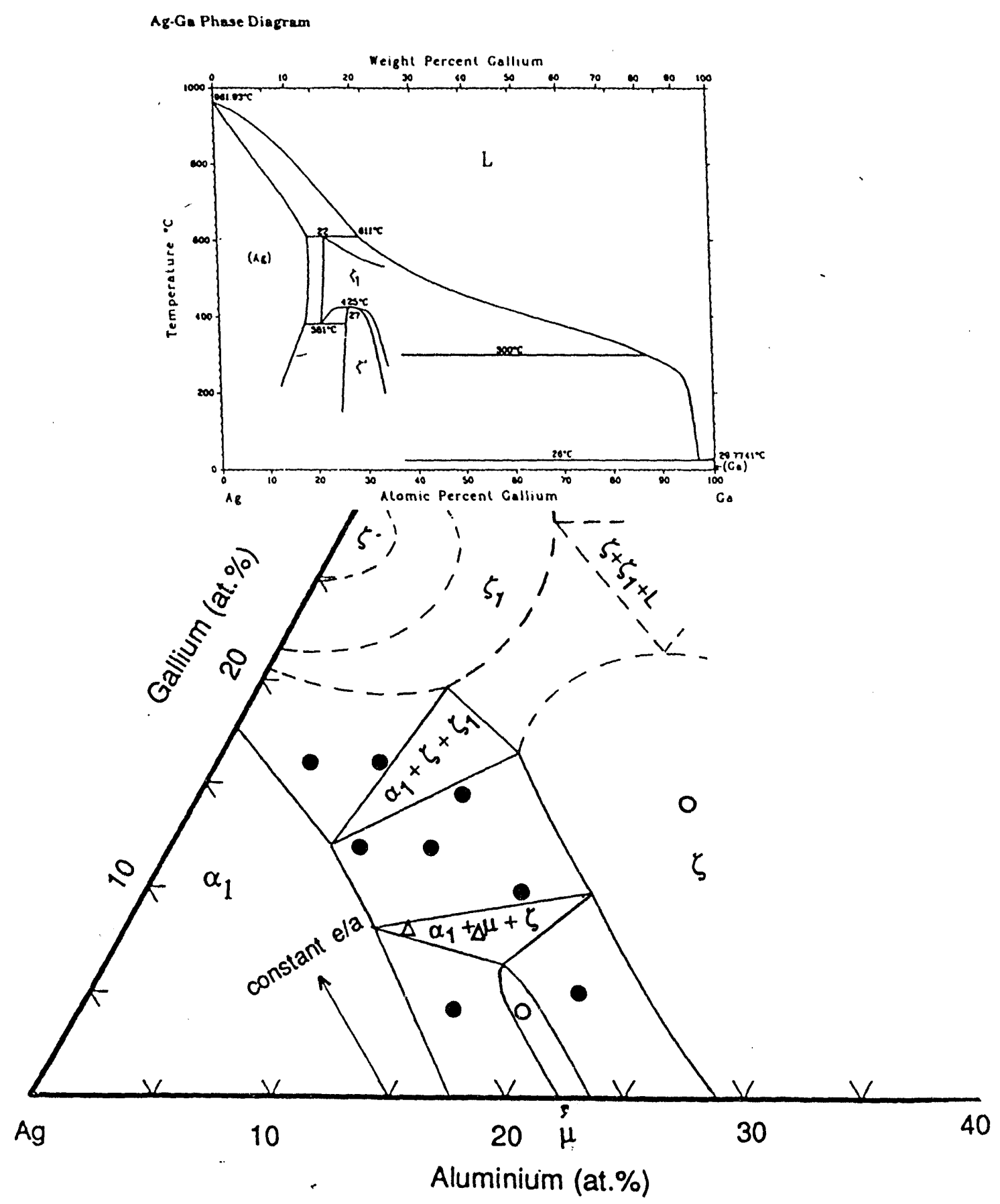

Fig. 2 


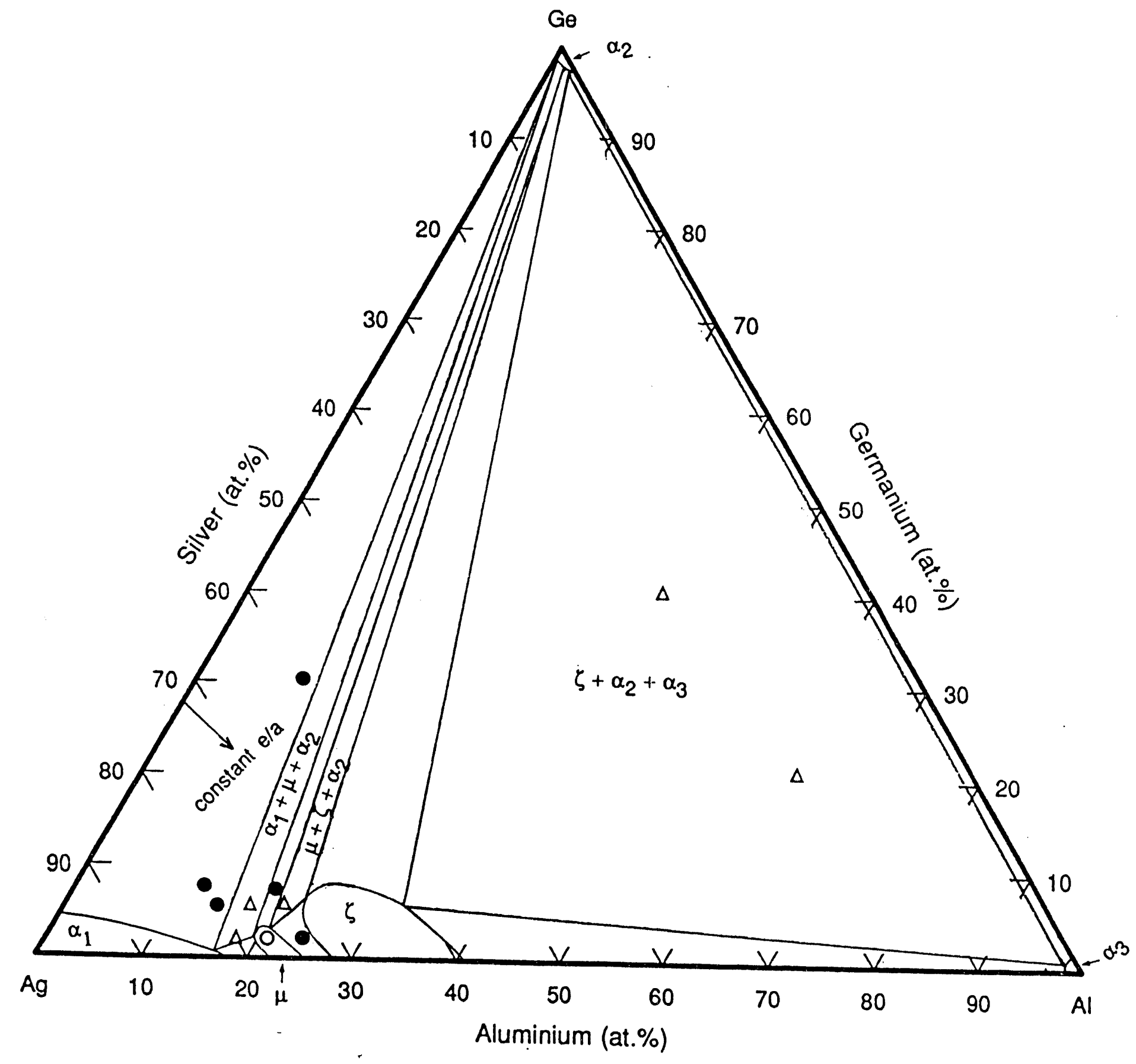

Fig. 3 

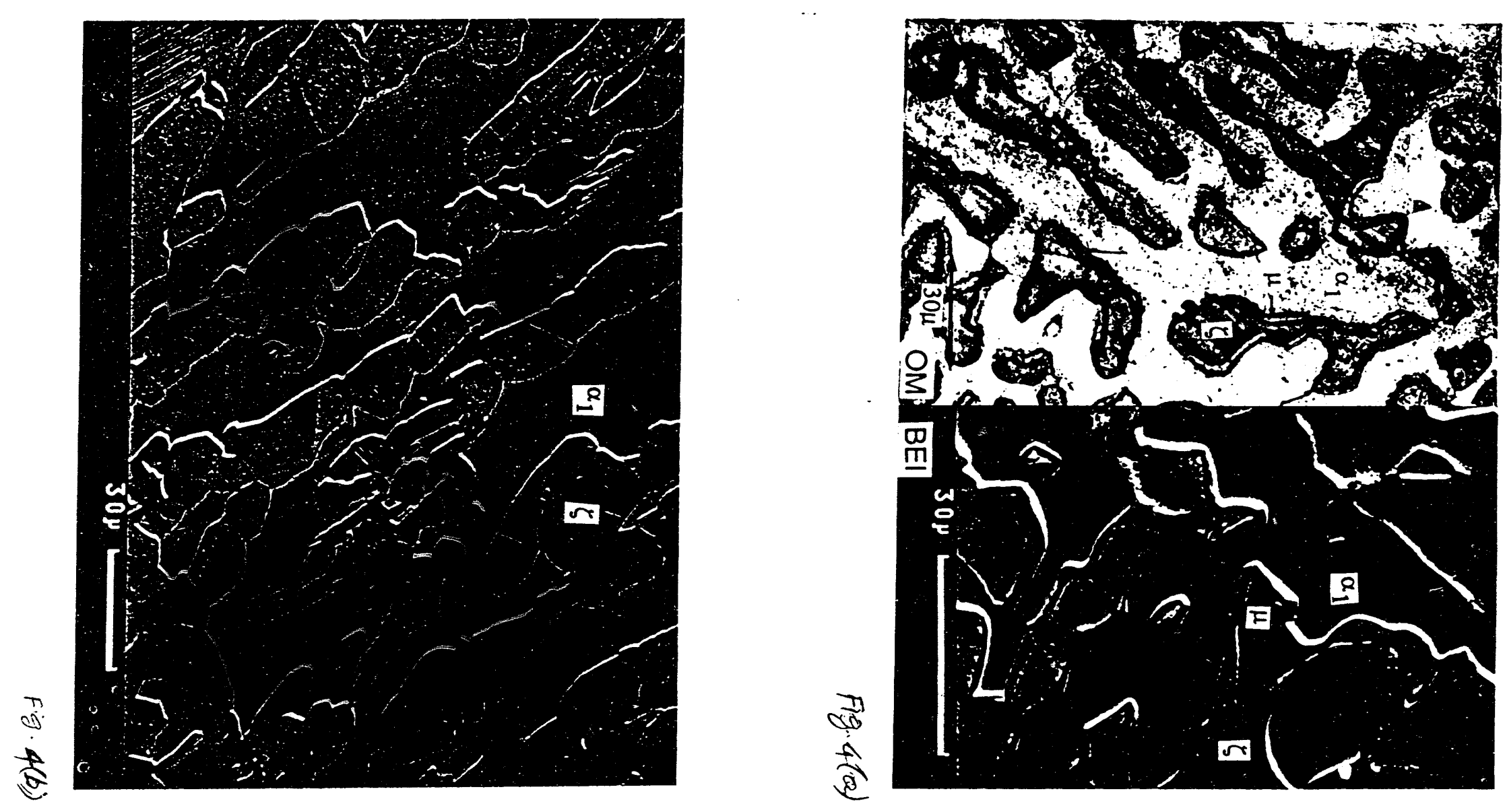


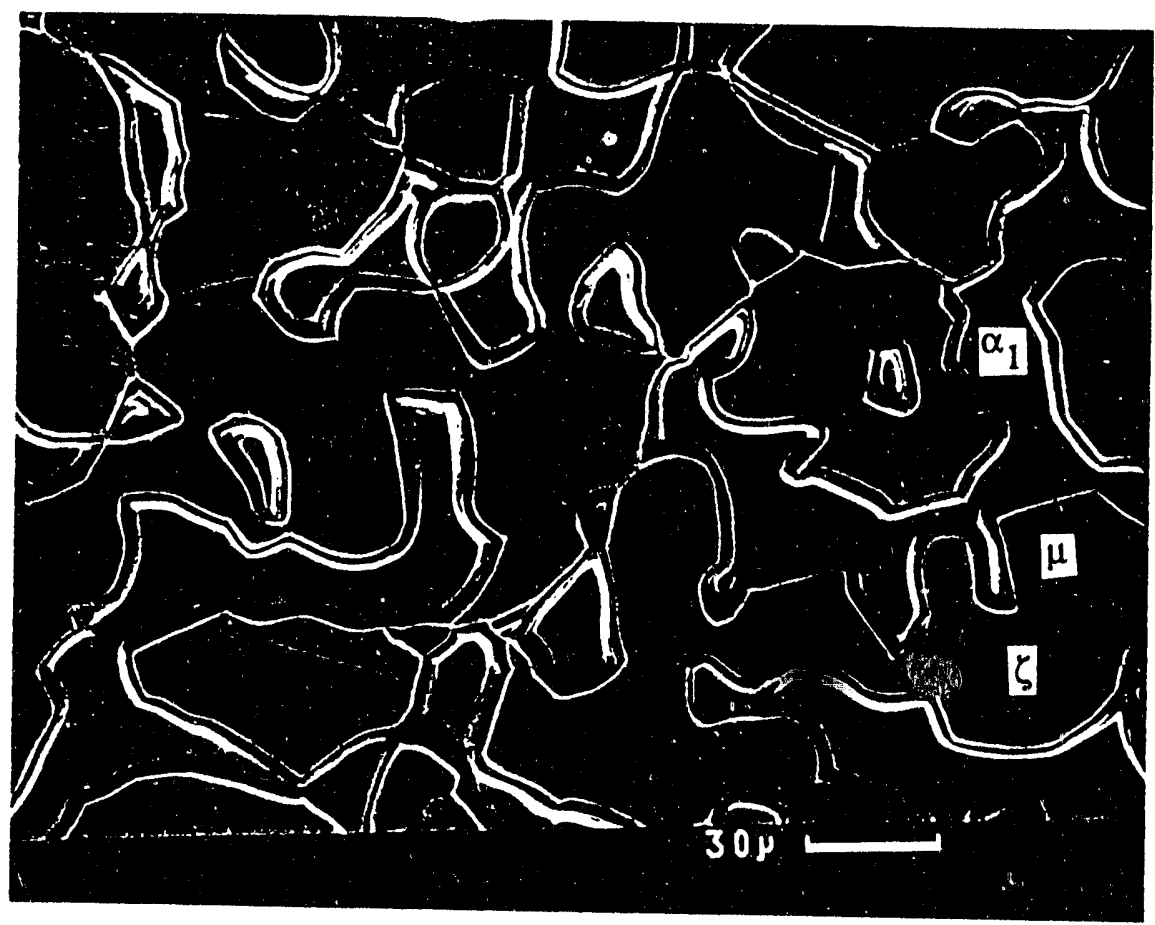

Fin. $4(c)$

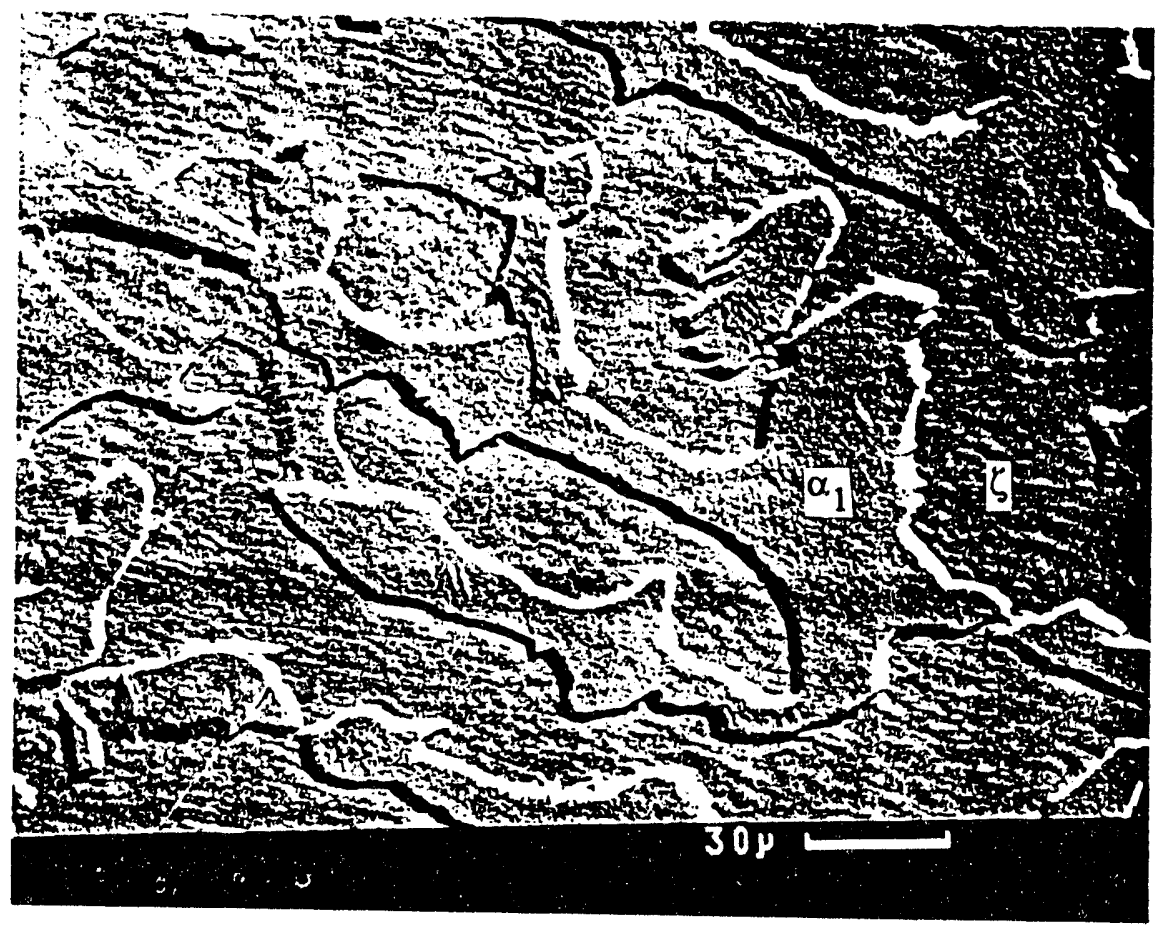

F:g. 4 (d) 


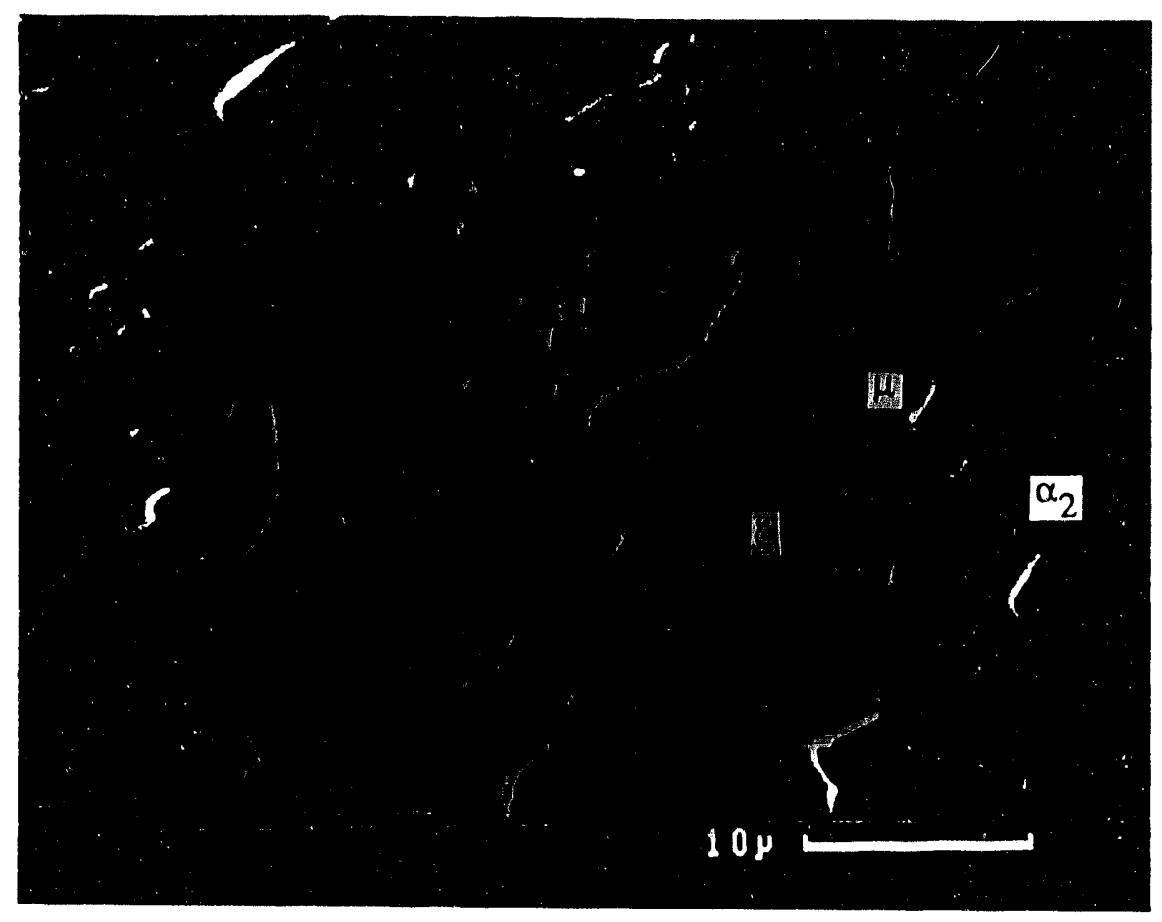

Fig. $4(e)$

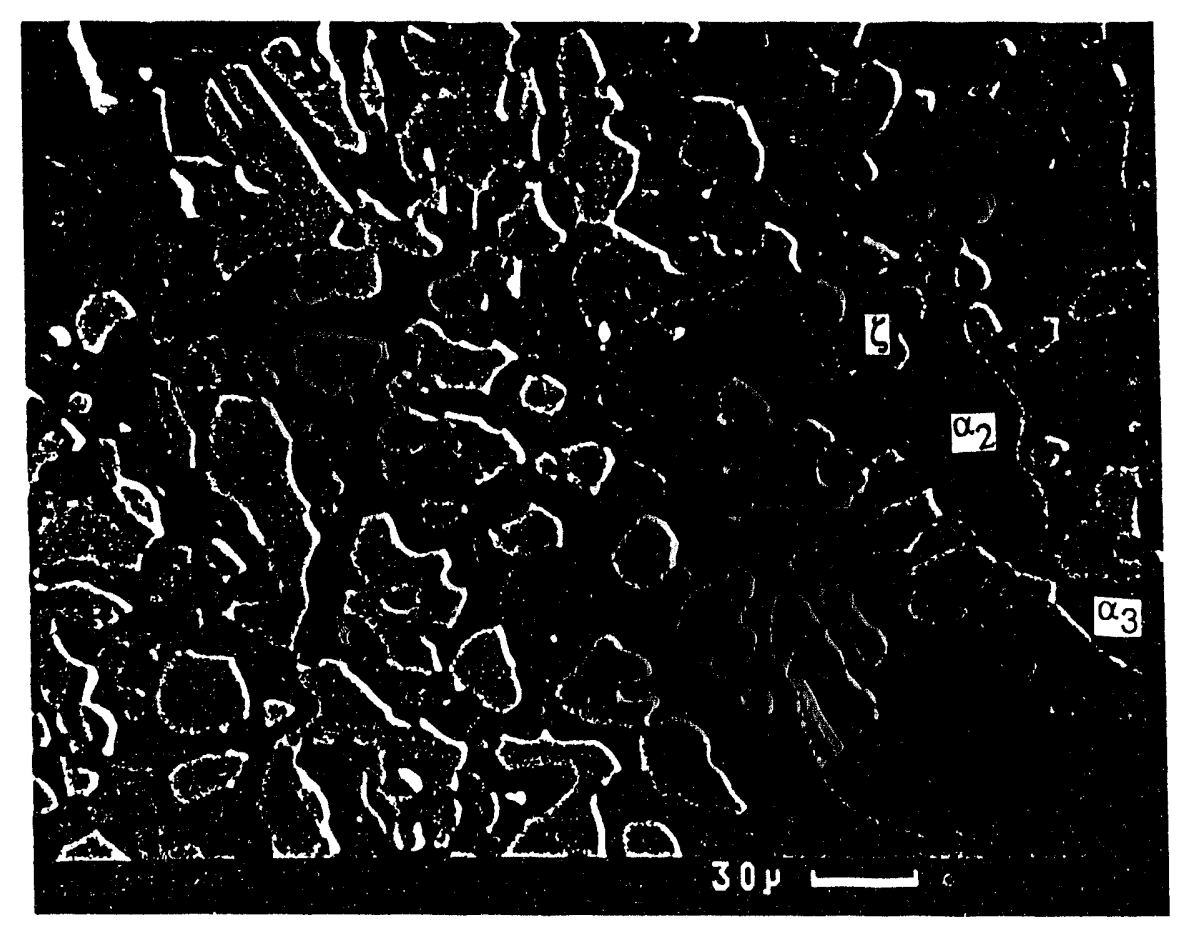

Fig. $4(f)$ 

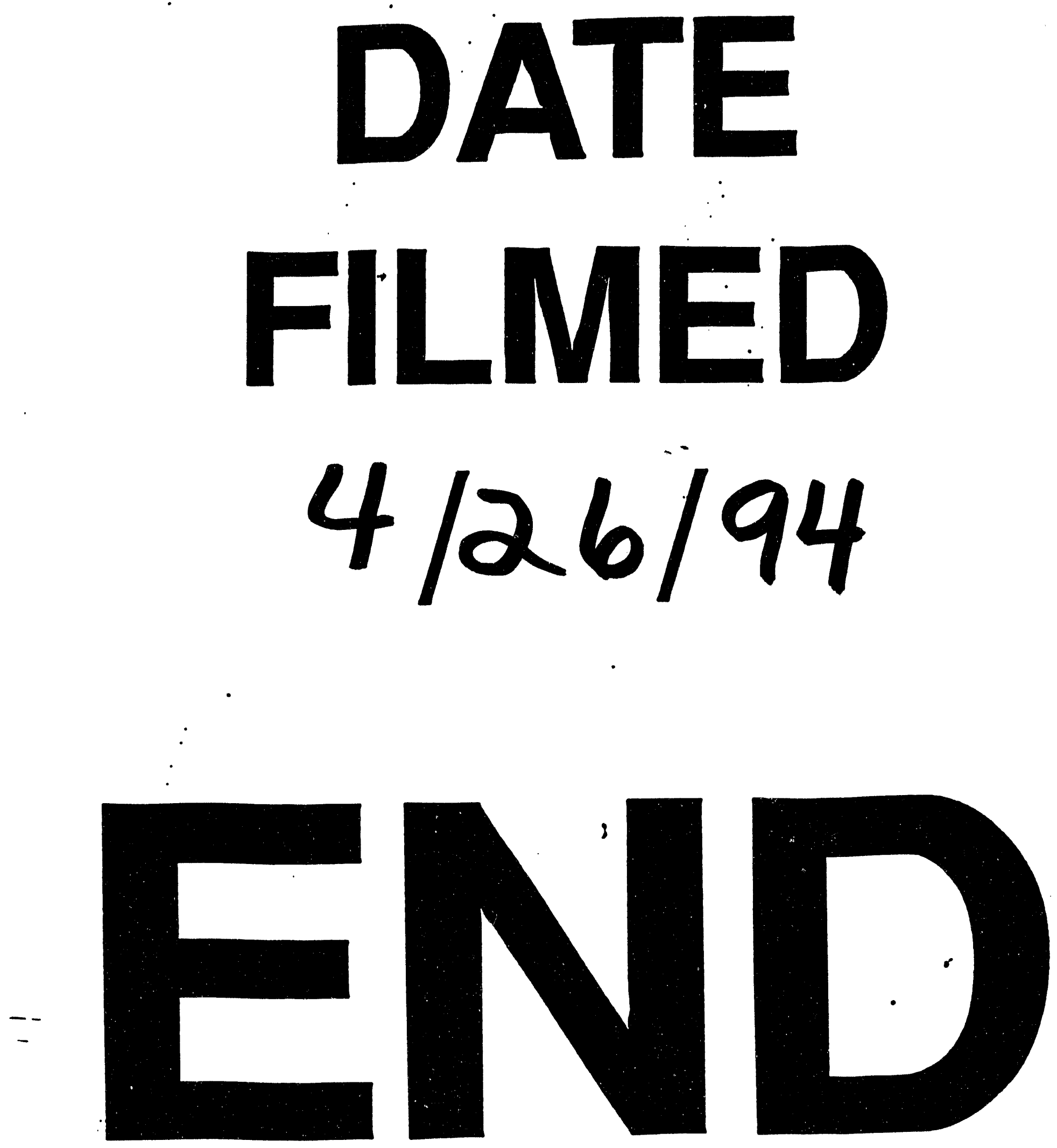
